South African Journal of Geomatics, Vol. 6. No. 3, October 2017

\title{
Application of semi-automated settlement detection for an integrated topographic map information system update in South Africa

\author{
L.Ngcofe ${ }^{1}$, T.Rambau ${ }^{1}$, M. McCalachan ${ }^{1}$, F. Hantibi ${ }^{1}$, N. Mudau ${ }^{2}$ \\ ${ }^{1}$ Department of Rural Development and Land Reform \\ Directorate: National Geo-Spatial Information \\ E-mail: Luncedo.Ngcofe@ drdlr.gov.za \\ ${ }^{2}$ South African National Space Agency \\ Earth Observation \\ Email: nmudau@sansa.org.za
}

DOI: http://dx.doi.org/10.4314/sajg.v6i3.3

\begin{abstract}
Complete, accurate and up-to-date topographic data is of vast importance as it is widely required by different government agencies, non-governmental organisations, the private sector as well as the general public for urban mapping, rural development and environmental management, to mention but a few applications. Efficient semi-automatic methods for detecting settlements as change area indicators are required in order to achieve a sustainable up-to-date topographic database. This study reviewed the capability of geographic object based image analysis (GEOBIA) as a semi-automated method for settlement detection using 2012 SPOT 5imagery in the KwaZulu-Natal Province, South Africa.

The application of GEOBIA provide the ability to segment imagery into areas resembling features of interest. For this study GEOBIA settlement detection provided $70.7 \%$ overall accuracy while the existing semi-automated South African global human settlement layer (SA_GHSL) had 60\% overall accuracy. These results presents an opportunity to apply GEOBIA semi-automated method to target areas of new settlement development more efficiently and with consistent repeatable manner. Thus assisting topographic update analyst to be drawn to more areas of new settlement development at an enhanced efficient rate. However the spectral variability of roof tops which are prominent identifiable feature by remote sensing for settlement areas prove to be the most challenging obstacle towards semiautomated settlement detection.
\end{abstract}




\section{Introduction}

The changes to the landscape are constantly occurring both naturally and human induced. It is essential for these changes to be regularly detected and captured for updated topographic information in order to reflect the current status of the landscape (Duncan \& Smit, 2012; Knudsen \& Oslen, 2003). Chen et al., (2014) concur highlighting the importance of topographic information applications for different government agencies, non-governmental organisation, private sector and citizens at large.

The Chief Directorate: National Geo-Spatial Information (CD: NGI), as one of its mandates, needs to provide the national topographic map information of the country. In doing so the organisation has developed an integrated topographic information system (iTIS) for the geo-spatial capture of the 1: 50000 scale topographic data product. The Spatial Data Infrastructure Act (SDI) 54 of 2003 provides CD: NGI with the responsibility to accurately maintain and frequently update the iTIS. The CD: NGI is therefore in the process of updating and maintaining the iTIS. The map updating and revision process is based on a data holistic approach, where for each new 1: 50000 map, all topographic data are collected in vector form, symbolised and validated. The map updates have been carried out as a full remapping of South Africa by manual detection and registration of the changes from aerial photographs. The current method of updating the iTIS is based on a five year revision cycle of all features using aerial photographs. This is due to the three year flying programme for capturing aerial photographs for the whole country and the compilation programme (entailing orthorectification) of the captured aerial photographs.

The current method has significant challenges as the manual approach has proved to be time and human resource consuming, which is not a unique problem as also experienced by mapping agencies around the world (Le Bris \& Chehata, 2011). This has resulted to certain areas of the country within the iTIS geo-spatial database to be continuously out-dated. Furthermore, in South Africa the compilation programme is forced to work in areas of the country that might have had little or no change due to the flying programme covering areas with no or little activities. The availability of new satellite sensors providing high spatial resolution and frequent data capture can be used to fast track topographic mapping updates. These include satellites like IKONOS, Quickbird, WorldView and SPOT to mention but a few. 
The most abundant information for the updates of topographic data is due to anthropogenic changes such as streets, roads, buildings and other infrastructures like power lines etc. (Knudsen \& Oslen 2003; Barber et al., 2008), which are instigated by fast infrastructure developments in order to meet economic needs of the country. These changes are largely experienced when there are new settlement developments, thus leading to an urgent need for an up-to-date topographic information more than ever. The application of settlement detection as an indicator of where major landscape changes occur to improve the iTIS database update is proposed for this study. This leads to the aim of the study which seeks to investigate the geographic object based image analysis (GEOBIA) as the semiautomated settlement detection from satellite imagery for the advancement of the iTIS geospatial update.

\section{Study area}

The study area is located in the KwaZulu-Natal Province characterised by an urban and rural area respectively (Figure 1). The choice of this study area has been due to the recent manual updating of the area using the 2012 aerial imagery. The study area covers $892.6 \mathrm{~km}^{2}$ of $2930 \mathrm{DD}$ and $2931 \mathrm{CC}$ sheet of 1: 50000 scale.

For the investigation of semi-automated settlement detection, SPOT 5, 2012 imagery has been used. The SPOT 5 imagery consist of four multispectral (Blue, Green, Red \& Near Infrared) bands and one panchromatic band. The multispectral bands have a spatial resolution of 10 meters and 2.5 meters for panchromatic band. The multispectral bands were pansharpened to 2.5 meter resolution in order to make use of spectral information and spatial accuracy of both image resolutions. The study area (Figure 1) is displayed using 321 band combination with red highlighting vegetation, cyan highlighting settlements with water shown as blue. 


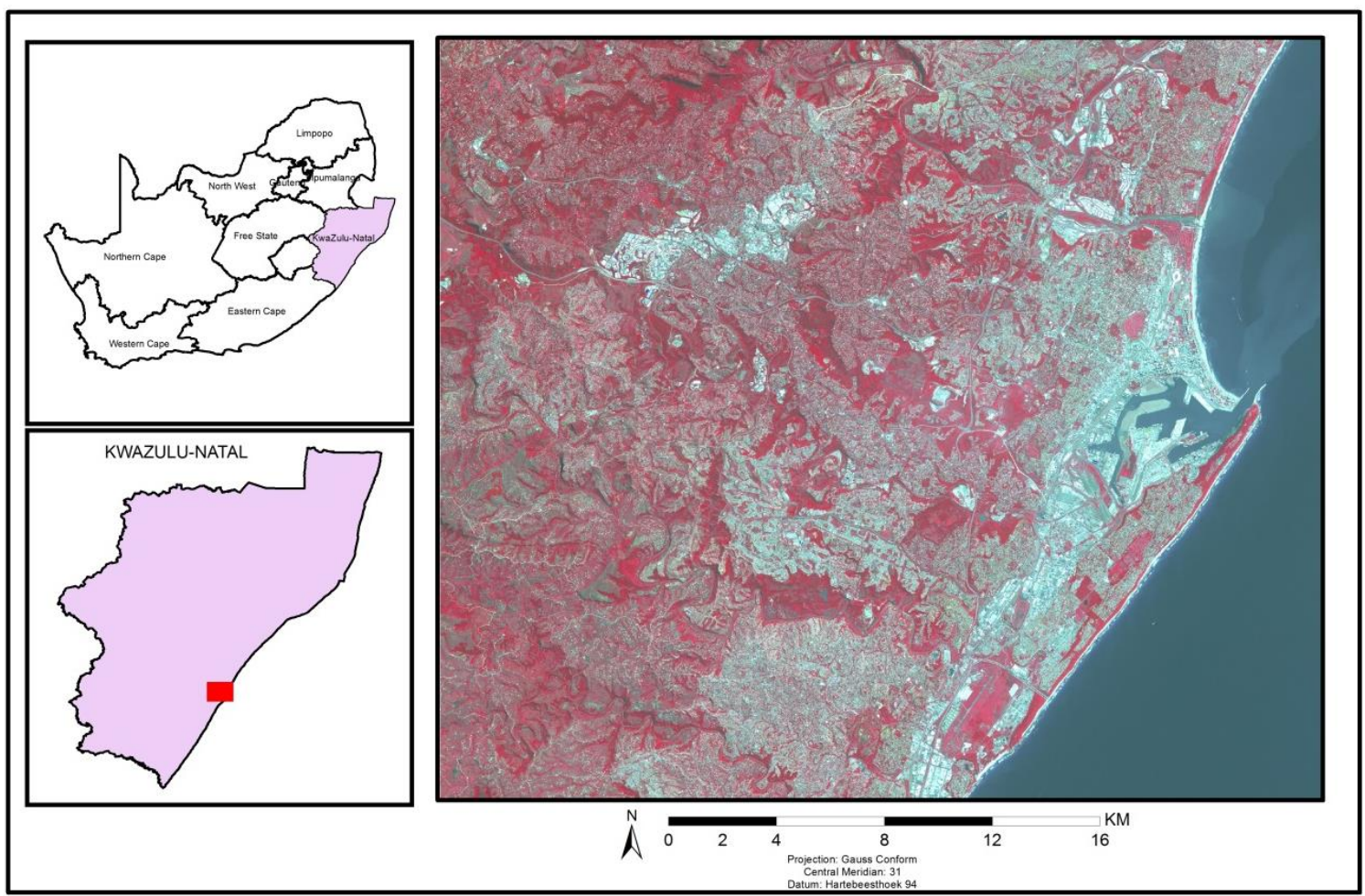

Figure 1: Location of the study area (2930DD and $2931 \mathrm{CC}$ of 1: 50000 scale) in KwaZuluNatal Province. The image is displayed as a false colour composite (RGB, 321) with red highlighting vegetation, cyan indicating settlement, and blue as water.

\section{Methodology}

This study investigated GEOBIA semi-automated method for settlement detection.

\subsection{Geographic Object Based Image Analysis (GEOBIA)}

The GEOBIA is defined as a discipline to develop theory, methods and tools for replicating and improving human interpretation of remotely sensed imagery in an automated or semi-automated manner (Hay \& Castilla, 2008; Blaschke \& Hay, 2001). GEOBIA has become accepted as an efficient method for extracting detailed information from very high spatial resolution satellite imagery over the past decade (Belgiu \& Drăgut, 2014; Blaschke, 2010). However, it is still regarded as a relatively new approach for earth observation image analysis when compared to traditional image (pixel) analysis. The GEOBIA involves the partitioning of a scene into discrete entities or segments from which meaningful image objects, based on their spatial and spectral attributes can be generated (Desclee et al., 2006; Gao \& Mas, 2008; Baatz \& Schape 2000). The principal idea is that meaningful information 
is not presented in individual pixels but in meaningful image objects and their mutual relationships (Schiewe, 2002).

This study concentrated on multiresolution segmentation (MRS) model implemented in eCognition software (Definiens, 2007). MRS is a bottoms-up region-merging technique that partitions the image into image objects on the basis of homogeneity criteria, controlled by user-defined parameters such as colour, shape, compactness/smoothness and scale. The combination of these parameters results in different image object and getting the correct object is trial-and-error process. Through different trial-and-error segmentation parameter investigations, suitable objects of interest were obtained. This entailed scale of 20, colour of 0.8 and smoothness of 0.5 parameters. This resulted to 23759 objects for analysis for the study area.

The next step was to determine variable obtained from image segmentation to classify the image. There are several variable that are generated by eCognition software to assist towards object feature classification. These include: layer values, geometry, position, texture, hierarchy, thematic attributes (

Figure 2). The layer value option entails spectral statistics such as mean value and mean brightness for image reflectance bands together with capability of further applying band ratio combinations. Under the texture and geometry option also several alternatives are applicable (such as length/width under extend and asymmetry under shape properties). Under the level co-occurrence matrix (GLCM) the study explored the contrast textual measurements developed by Haralick et al., (1973). This study assessed the following variables, mean brightness, density, length/width and band ratios. After determining the variable to be further used for settlement detection, the actual classification based on rule set was applied. 


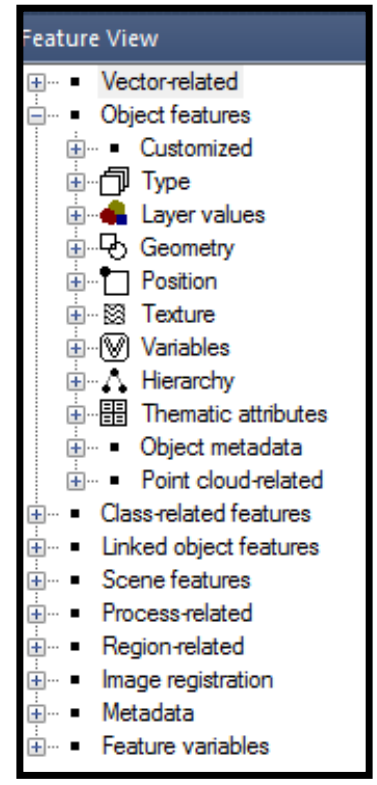

Figure 2: Various variable parameters available in eCognition software

The rule based classification step entails determining the rule and values for each of the chosen variable feature to attain class features of interest. The following classes: vegetation, water, roads, settlements and bare ground were discriminated

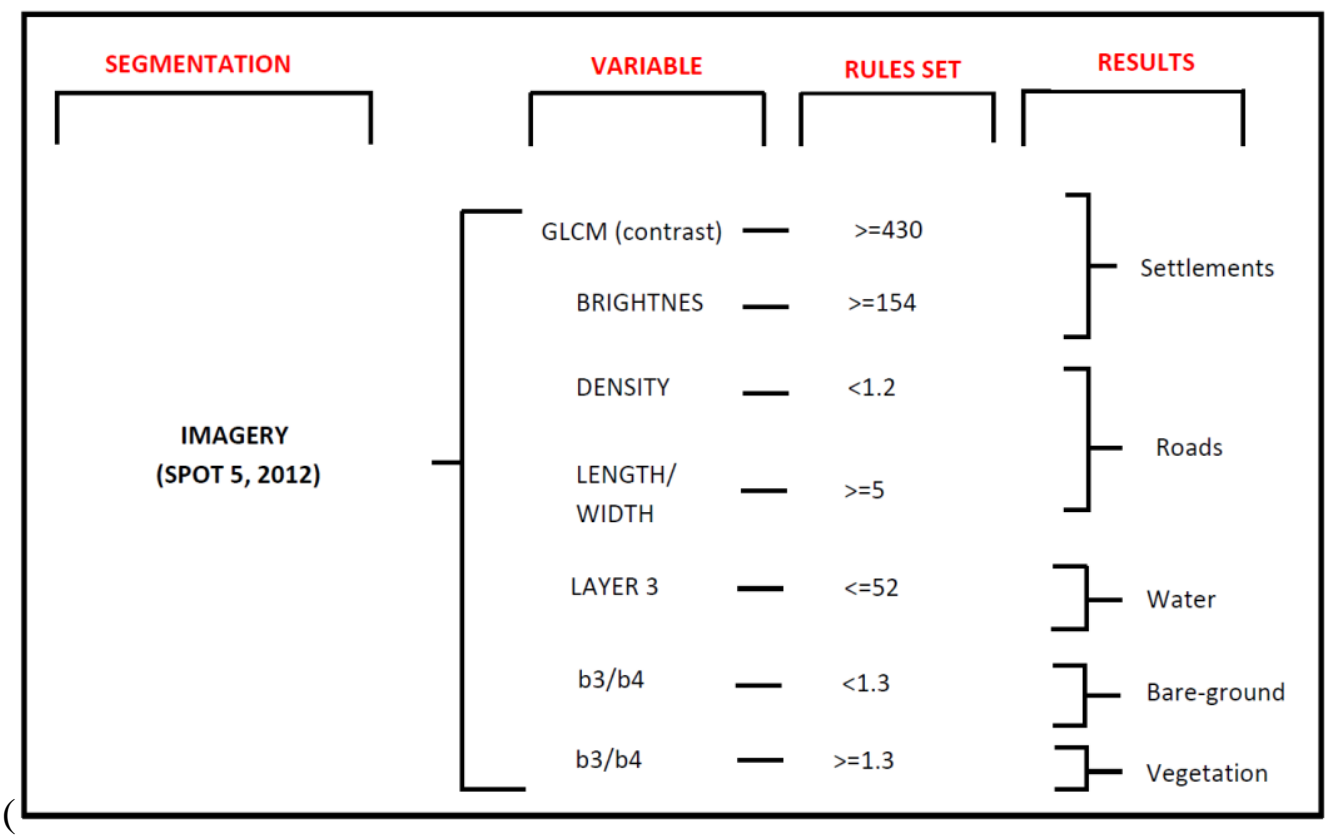

Figure 3). The inclusion of discriminated other classes (vegetation, bare ground, water \&roads) was due to enhance settlement detection when these classes were distinctly separated. The final step was to export the results to ArcGIS 10.2.2 for further analysis. The settlement class was extracted from other classes for precise examination and accuracy assessment. 


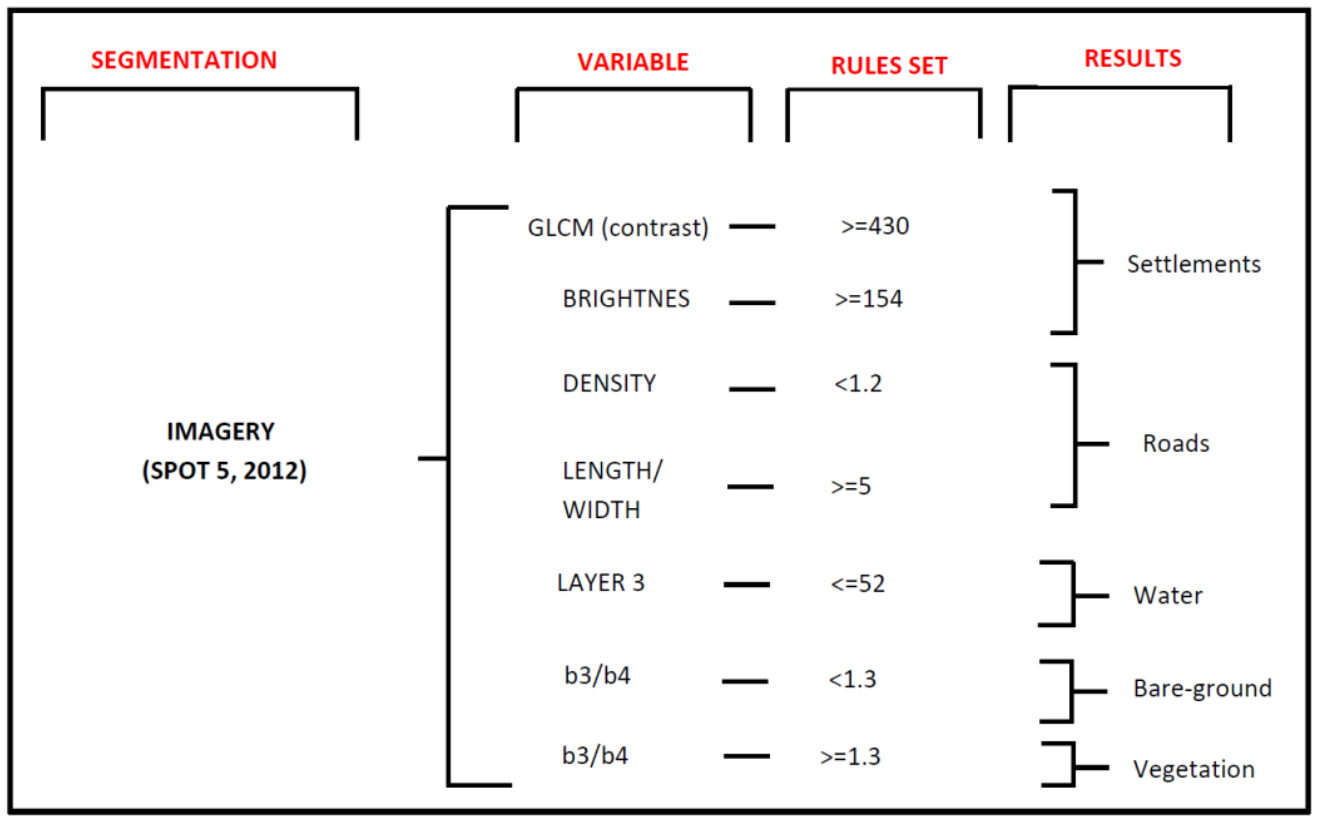

Figure 3: The methodological approach for image classification from on rule based technique.

\section{Results and Discussions}

For the GEOBIA application the study area was characterised into five classes namely: vegetation, water, roads, settlements and bare ground. The purpose of including other classes for classification was to discriminate those areas that potentially have similar spectral reflectance to the class of interest (the settlements class). For settlements detection, the roof tops are the prominent feature of buildings which are identifiable by remote sensors. The large variability in material composition, colour, shape, size and orientation of the roof tops makes it difficult to grasp sematic properties by any consistent physical definable attributes (Asmat \& Zamzami, 2011; Le Bris \& Chehata, 2011). This has proved to be evident with the results from GEOBIA where by not full cover of the roof top could be captured or detected (Figure 4). 


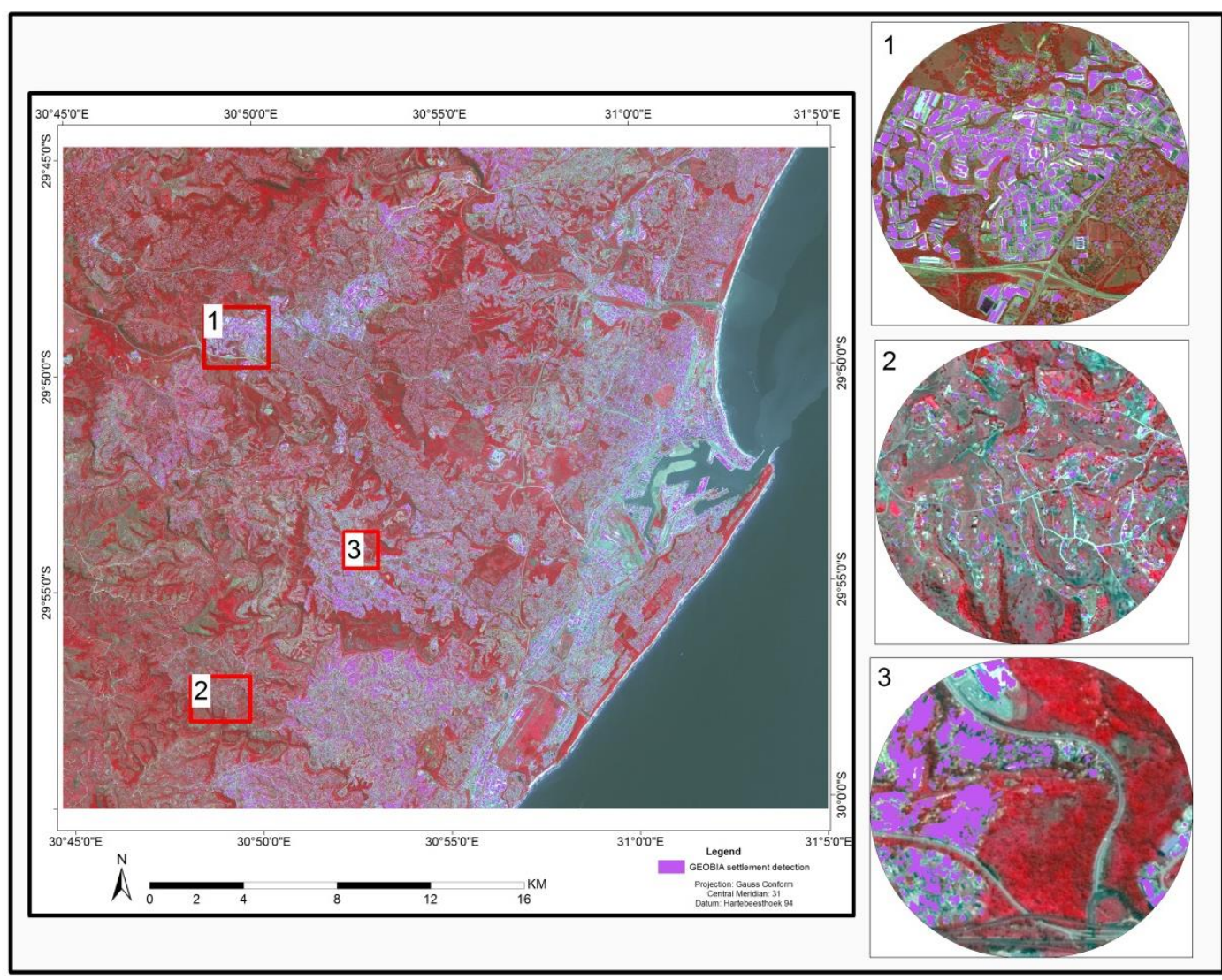

Figure 4: Geographic Object Based Image Analysis (GEOBIA) settlement detection results overlaid on SPOT5, 2012 band combination 321 (RGB). The zoomed in-insert (1,2 \&3) reveal settlement detection capability of roof tops. 
South African Journal of Geomatics, Vol. 6. No. 3, October 2017

To attain better understanding of GEOBIA settlement detection, visual analysis of results were compared to the existing semi-automated settlement layer called South African global human settlement layer (SA_GHSL) produced by the South African National Space Agency (SANSA).The SA_GHSL was conducted using SPOT 5, 2012 imagery as utilised to derive settlements by GEOBIA. The detailed methodology used to derive SA_GHSL has been explained by Kemper et al., 2015. Through visual analysis the GEOBIA technique was observed to better identify the roof tops while SA_GHSL better identified roof top edges (Figure 5Figure 6). The ability to identify roof tops by GEOBIA is directly related to the capability of an image segmentation process that seeks to also resemble the shape of the features of interest, while variability of material composition remained a stabling block for full detection.

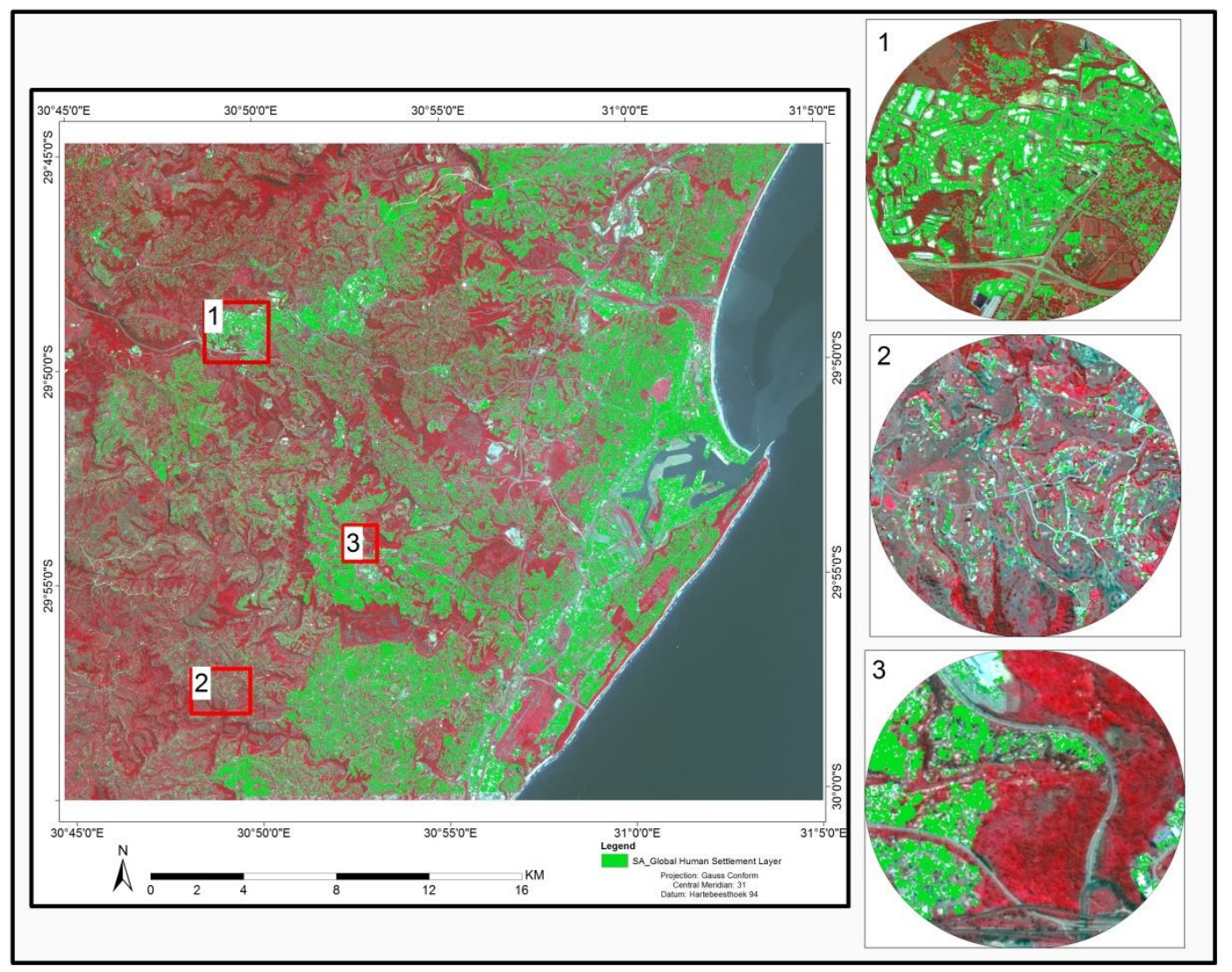

Figure

5: South African Global Human Settlement Layer (SA_GHSL) settlement detection results overlaid on SPOT5, 2012 band combination 321 (RGB). The zoomed in-insert (1,2 \&3) reveal settlement detection capability of roof tops. 


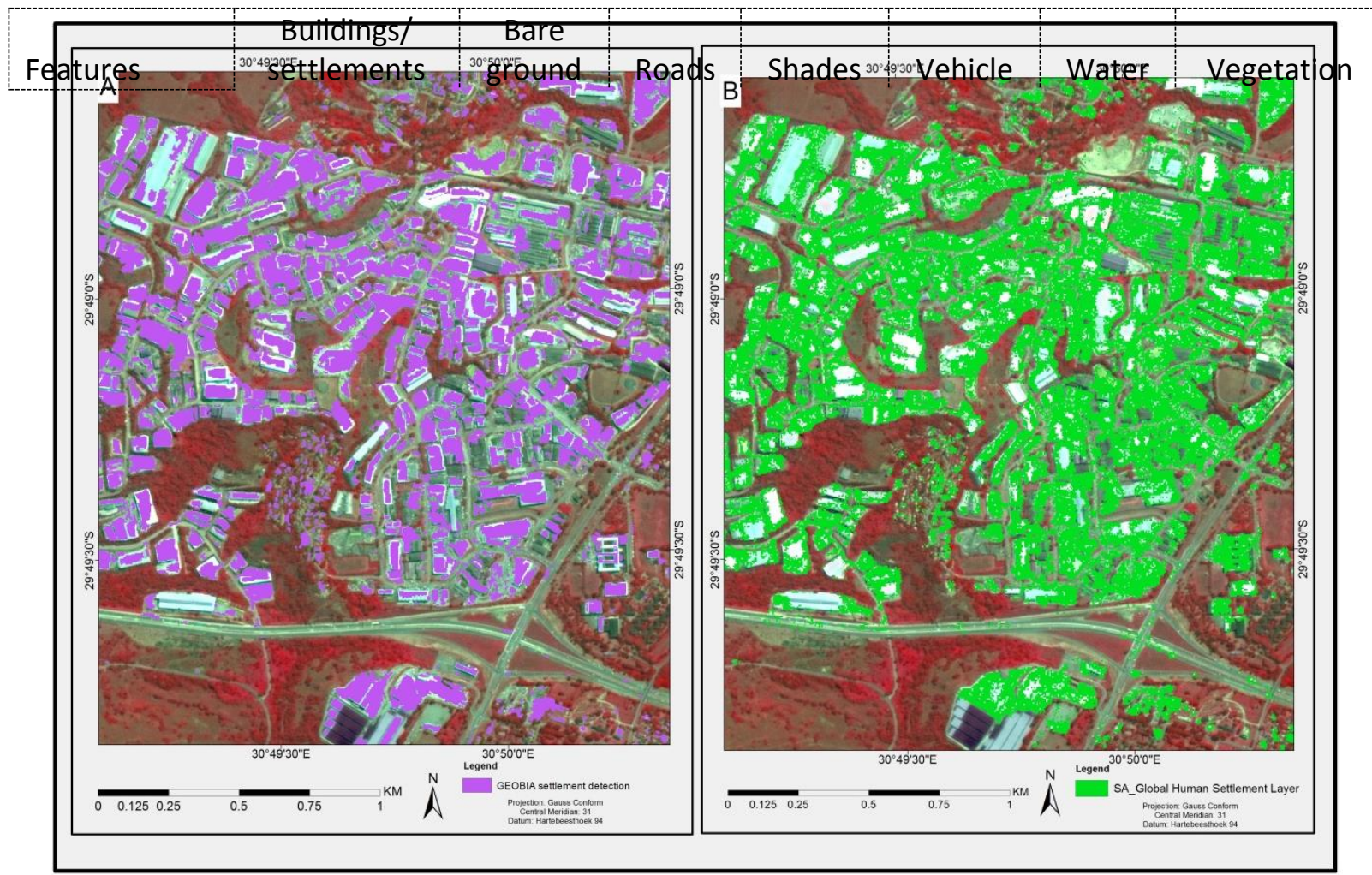

Figure 6: Visual identification of settlements (buildings) between A) Geographic Object Based Image Analysis (GEOBIA) semi-automated detection against B) South African Human Settlement Layer (SA_GHSL).

An error matrix accuracy assessment (Congalton \& Green, 2009; Senseman et al., 1995) was conducted for quantitative measure of the semi-automated settlement detection results. The accuracy assessment was based on the generation of 65 random points from the manual digitised settlement layer by CD: NGI. This carried an assumption that every random selected point would be detected by the semi-automated settlement detection. The selected points were then visually classified using 2012 aerial imagery with 0.5 meter resolution into the following classes: buildings, bare ground, roads, shades, vehicle, water, and vegetation. The 65 random points were then examined and determined whether they were correctly detected or not by the semi-automated settlements results. The overall accuracy assessment results for correctly classified semi-automated settlements detection was 70.8\% for GEOBIA (Table 1) and $60 \%$ for SA_GHSL (Table 2). It has been observed that for GEOBIA method, only 2 out of the 65 random points were not detected resulting to only $3.07 \%$ omission points for analysis. While for the SA_GHSL, 12 out of 65 random points detected resulting to $18.5 \%$ omission points for analysis. 
South African Journal of Geomatics, Vol. 6. No. 3, October 2017

\begin{tabular}{|c|c|c|c|c|c|c|c|c|}
\hline Settlements & 45 & 5 & 3 & 5 & 1 & 1 & 2 & 62 \\
\hline Not detected & 2 & 1 & Reference & frompaeria & imagery & 0 & 0 & 3 \\
\hline Bare ground & 0 & 0 & 0 & 0 & 0 & 0 & 0 & 0 \\
\hline Shades & 0 & 0 & 0 & 0 & 0 & 0 & 0 & 0 \\
\hline Vehicle & 0 & 0 & 0 & 0 & 0 & 0 & 0 & 0 \\
\hline Water & 0 & 0 & 0 & 0 & 0 & 0 & 0 & 0 \\
\hline Vegetation & 0 & 0 & 0 & 0 & 0 & 0 & 0 & 0 \\
\hline Column total & 47 & 6 & 3 & 5 & 1 & 1 & 2 & 65 \\
\hline
\end{tabular}

Table 1: Accuracy assessment of GEOBIA

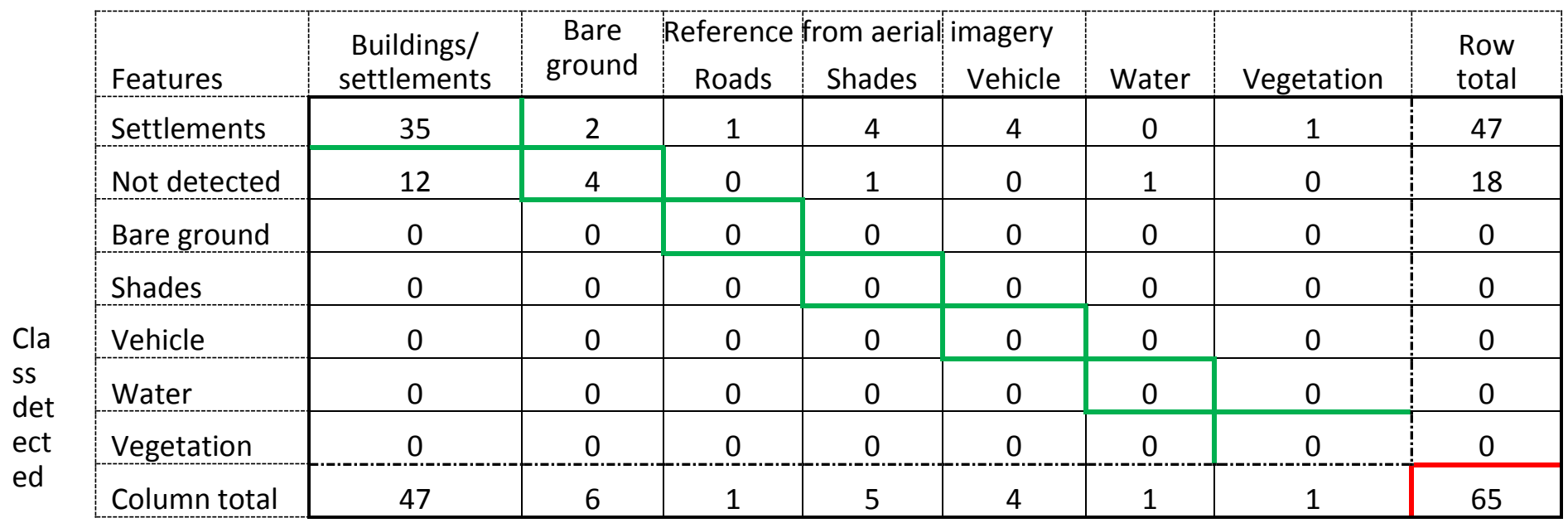

Table 2: Accuracy assessment of SA_GHSL

\section{Conclusion}

This study demonstrates the use of high-resolution imagery to facilitate settlement detection in order to fast tracking topographic map updates. The semi-automated settlement detection by GEOBIA approaches using 2012 SPOT 5 imagery obtained $70.8 \%$ accuracy. The ability to obtain high accuracy results $(70.8 \%)$ with minimum omission error $(3.07 \%)$ for GEOBIA settlement detection provides an opportunity to apply this method to target areas of new settlement developments more efficiently and in a consistent repeatable manner. With the successful launch of SPOT 6 in 2012 and SPOT 7 in 2014 with 6 meter multispectral bands (Blue, Green, Red, Near Infrared) and 1.5 meter panchromatic band presents potential capability for increase of semi-automated settlement detection accuracy. 


\section{Acknowledgment}

The authors would like to thank Debbie Sutherland for her tireless contribution towards this paper. Thanks also goes to anonymous reviewers for their contributions in strengthening this paper.

\section{REFERENCES}

Asmat, A., Zamzami, S.Z., 2012. Automated house detection and delineation using optical remote sensing technology for informal human settlement. Procedia-Social and Behavioral Sciences, 36: 650-658.

Baatz, M., Schape, A., 2000. Multiresolution segmentation: an optimization approach for high quality multi-scale image segmentation. In Strobl, J., Blaschke, T., Griesbner,G., (Eds) Angewandie Geographische Informations-sverabeitung VII, Wichmann Verlag, Karsrushe, Germany, 12-23.

Barber, D.M., Holland, D., Mills, J.P., 2008. Change detection for topographic mapping using three dimensional data structure. The International Archives of the Photogrammetry, Remote Sensing and Spatial Information Sciences, Beijing.

Belgiu, M., Dragut, L., 2014. Comparing supervised and unsupervised multiresolution segmentation approaches for extracting buildings from very high resolution imagery. ISPRS Journal of Photogrammetry and Remote Sensing 96: 67-75.

Blaschke, T., 2010. Object based image analysis for remote sensing. ISPRS Journal of Photogrammetry and Remote Sensing, 62: 2-16.

Blaschke, T., Hay, G.J., 2001. Object-oriented image analysis and scale-space: Theory and methods for modelling and evaluating multiscale landscape structure. International Archives of Photogrammetry and Remote Sensing, 4 (34): 22-29.

Chen, J., Wang, D., Zhao,R., Zhang,H., Liao, A., Liu, J., 2014. Fast updating of national Geo-Spatial databases with high resolution imagery: China's methodology and experiences. The International Archives of the Photogrammetry, Remote Sensing and Spatial Information Science, 41-50.

Congalton, R.G., Green, K., 2009. Assessing the accuracy of remotely sensed data: Principles and Practices $2^{\text {nd }} E d$. Taylor and Francis Group, New York.

Definiens developer 7, 2007. Reference book. Definiens A.G., Munchen. http://ecognition.cc/download/userguide.pdf. Accessed 17June 2017.

Desclee, B., Bogaert, P., Defourny, P., 2006. Forest change detection by statistical object-based method. Remote Sensing of Environment, 102: 1-11.

Dey, V., Zhang, Y., Zhongm,M., 2010. A review on image segmentation techniques with remote sensing perspective. ISPRS TC VII Symposium, Vienna, Austria, 31-42.

Duncan, P., Smit, J., 2012. An investigation of automatic change detection for topographic updating. International Archives of the Photogrammetry, Remote Sensing and Spatial Information Sciences. ISPRS congress, Melbourne, Australia. 
Gao, Y., Mas, J.F., 2008. A comparison of the performance of pixel based and object based classification over images with various spatial resolution. Journal of Earth Sciences 2 (1): 27-35.

Haralick, R., Shanmugam, K., Dinstein, I., 1973. Textural features for image classification. IEE Transactions on Systems Man and Cybernetics. 3(6): 610-621.

Hay, G.J., Castilla, G., 2008. Geographic Object-Based Image Analysis (GEOBIA): A new name for a new discipline. In: Object-based image analysis: Spatial concept for knowledge-driven remote sensing applications edited by Blascke T and Lang S. (Springer Publishers, Heidelberg), 93-112.

Kemper, T., Mudau, N., Mangara, P., Pesaresi, M., 2015. Towards an automated monitoring of human settlements in South Africa using high resolution SPOT satellite imagery. 36 International Symposium on Remote Sensing of Environment, 11-15 May, Berlin, Germany.

Knudsen, T., Olsen, B.P., 2003. Automated change detection for updates of digital map databases. Photogrammetric Engineering and Remote Sensing, 69 (11): 1289-1296.

Le Bris, A., Chehata, N., 2011. Change detection in a topographic building database using submetric satellite images. International Archives of Photogrammetry, Remote Sensing and Spatial Information Sciences, 38 (3/W22).

Schiewe, J., 2002.Segmentation of high-resolution remotely sensed data-concepts, applications and problems. International Archives of the Photogrammetry, Remote Sensing and Spatial Information Sciences, 34: 380-385.

Senseman G.M., Bagley C.F., Tweddale S.A., 1995. Accuracy assessment of the discrete classification of remotely-sensed digital data for land cover mapping. USACERL Technical Report EN-95/04. 